\title{
Surgical management and outcome of patients with chronic thromboembolic pulmonary hypertension: Results from an international prospective registry
}

\author{
Eckhard Mayer, MD, ${ }^{\mathrm{a}}$ David Jenkins, FRCS, ${ }^{\mathrm{b}}$ Jaroslav Lindner, MD, ${ }^{\mathrm{c}}$ Andrea D'Armini, MD, ${ }^{\mathrm{d}}$ \\ Jaap Kloek, MD, ${ }^{\mathrm{e}}$ Bart Meyns, MD, ${ }^{\mathrm{f}}$ Lars Bo Ilkjaer, MD, ${ }^{\mathrm{g}}$ Walter Klepetko, MD, ${ }^{\mathrm{h}}$ Marion Delcroix, MD, ${ }^{\mathrm{f}}$ \\ Irene Lang, MD, ${ }^{\mathrm{h}}$ Joanna Pepke-Zaba, MD, ${ }^{\mathrm{b}}$ Gerald Simonneau, MD, ${ }^{\mathrm{i}}$ and Philippe Dartevelle, $\mathrm{MD}^{\mathrm{j}}$
}

\begin{abstract}
Objective: Pulmonary endarterectomy is a curative surgical treatment option for the majority of patients with chronic thromboembolic pulmonary hypertension. The current surgical management and postoperative outcome of patients enrolled in an international registry on chronic thromboembolic pulmonary hypertension were investigated.
\end{abstract}

\begin{abstract}
Methods: The registry included newly diagnosed ( $\leq 6$ months) consecutive patients with chronic thromboembolic pulmonary hypertension from February 2007 to January 2009.

Results: A total of 679 patients were registered from 1 Canadian and 26 European centers, of whom 386 (56.8\%) underwent surgery. The median age of patients undergoing surgery was 60 years, and $54.1 \%$ were male. Previous pulmonary embolism was confirmed for $79.8 \%$ of patients. Perioperative complications occurred in 189 patients $(49.2 \%)$ : infection $(18.8 \%)$, persistent pulmonary hypertension $(16.7 \%)$, neurologic $(11.2 \%)$ or bleeding $(10.2 \%)$ complications, pulmonary reperfusion edema $(9.6 \%)$, pericardial effusion $(8.3 \%)$, need for extracorporeal membrane oxygenation (3.1\%), and in-hospital mortality due to perioperative complications $(4.7 \%)$. Documented 1 -year mortality was $7 \%$. Preoperative exercise capacity was predictive of 1 -year mortality. Postoperative pulmonary vascular resistance predicted in-hospital and 1-year mortality. In patients evaluated within 1 year after surgery, the median pulmonary vascular resistance had decreased from 698 to 235 dyn.s.cm ${ }^{-5}(95 \%$ confidence limit, 640-874 and 211-255, respectively, $\mathrm{n}=70$ ) and the median 6-minute walk distance had increased from 362 to $459 \mathrm{~m}$ (95\% confidence limit, 340-399 and 440-473, respectively, $\mathrm{n}=168$ ). New York Heart Association functional class improved with most patients progressing from class III/IV to class I/II.
\end{abstract}

Conclusions: Pulmonary endarterectomy is associated with a low in-hospital mortality rate and improvements in hemodynamics and exercise capacity. (J Thorac Cardiovasc Surg 2011;141:702-10)

\section{Earn CME credits at}

http://cme.ctsnetjournals.org

Chronic thromboembolic pulmonary hypertension (CTEPH) is caused by the obstruction of pulmonary artery branches by

From the Kerckhoff Heart and Lung Center, ${ }^{\text {a }}$ Bad Nauheim, Germany; Papworth Hospital, ${ }^{\mathrm{b}}$ Cambridge, United Kingdom; General University Hospital, Charles University in Prague, ${ }^{\mathrm{c}}$ Prague, Czech Republic; San Matteo Hospital, University of Pavia, ${ }^{\mathrm{d}}$ Pavia, Italy; University of Amsterdam, ${ }^{\mathrm{e}}$ Amsterdam, The Netherlands; University Hospital Gasthuisberg, ${ }^{\mathrm{f}}$ Leuven, Belgium; Aarhus University Hospital, ${ }^{\mathrm{g}}$ Skejby, Aarhus, Denmark; Medical University of Vienna, ${ }^{\text {h }}$ Vienna, Austria; Service Pneumologie, Hôpital Antoine Béclère, ${ }^{i}$ Paris, France; and Marie-Lannelongue Hospital, ${ }^{\mathrm{j}}$ Le Plessis Robinson, France.

Grant support: This registry was supported by Actelion Pharmaceuticals Ltd.

Disclosures: E. Mayer has received fees for consulting or serving on advisory boards and lecture fees from Bayer-Schering and Actelion Pharmaceuticals Ltd. D. Jenkins has received fees for consulting or serving on advisory boards from Bayer. J. Lindner has received fees for consulting or serving on advisory boards from Bayer-Schering and lecture fees from Actelion Pharmaceuticals Ltd. A. M. D'Armini has received fees for consulting or serving on advisory boards from Pfizer and lecture fees from Actelion Pharmaceuticals Ltd. B. Meyns has received lecture fees from Circulite and Abiomed. L. B. Ilkjaer has received fees for consulting or serving on advisory boards from Bayer Health Care. W. Klepetko has received fees for consulting or serving on advisory boards from Astellas. M. Delcroix has received fees for consulting or serving on advisory boards from Actelion Pharmaceuticals single or recurrent episodes of pulmonary embolism and incomplete thrombus resolution. ${ }^{1}$ The subsequent increase in pulmonary vascular resistance (PVR) is believed to be due to mechanical obstruction by organized thrombus in proximal pulmonary arteries and to the development of progressive secondary arteriopathy in small pre-capillary pulmonary vessels. $^{2}$

Ltd and GlaxoSmithKline, and lecture fees from Pfizer and LungRx. I. Lang has received fees for consulting or serving on advisory boards and lecture fees from Actelion Pharmaceuticals Ltd, Pfizer, AOP Orphan Pharmaceutivals AG, Bayer, GlaxoSmithKline. J. Pepke-Zaba has received lecture fees from Actelion Pharmaceuticals Ltd, Pfizer, and Bayer. P. Dartevelle has nothing to disclose with regard to commercial support.

The CTEPH Registry is owned and managed by the Association for Research in CTEPH. The Association is headed by an Executive Board, composed of CTEPH experts. The Executive Board of the Association provided expert opinion on the registry design, CTEPH medical issues, and input into the analyses and publications.

Read at the 90th Annual Meeting of The American Association for Thoracic Surgery, Toronto, Ontario, Canada, May 1-5, 2010.

Received for publication April 30, 2010; revisions received Nov 10, 2010; accepted for publication Nov 12, 2010.

Address for reprints: Eckhard Mayer, MD, Kerckhoff Heart and Lung Center, D-61231 Bad Nauheim, Germany (E-mail: emayer@kkmainz.de). 0022-5223/\$36.00

Copyright (c) 2011 by The American Association for Thoracic Surgery doi:10.1016/j.jtcvs.2010.11.024 


$$
\begin{aligned}
& \text { Abbreviations and Acronyms } \\
& \qquad \begin{aligned}
\mathrm{CL} & =\text { confidence limit } \\
\mathrm{CT} & =\text { computed tomography } \\
\mathrm{CTEPH} & =\text { chronic thromboembolic pulmonary } \\
& \text { hypertension } \\
\mathrm{mPAP}= & \text { mean pulmonary artery pressure } \\
\mathrm{NYHA} & =\text { New York Heart Association } \\
\mathrm{OR} & =\text { odds ratio } \\
\text { PAH } & =\text { pulmonary arterial hypertension } \\
\text { PEA } & =\text { pulmonary endarterectomy } \\
\text { PVR } & =\text { pulmonary vascular resistance }
\end{aligned}
\end{aligned}
$$

CTEPH may develop in up to $4 \%$ of patients within the first 2 years after acute pulmonary embolism, ${ }^{3}$ and retrospective studies have described preceding venous thromboembolism in up to $69 \%$ of cases. ${ }^{4}$ Left untreated, the disease has a poor prognosis, proportional to the severity of pulmonary hypertension. ${ }^{5}$

Surgical pulmonary endarterectomy (PEA) is recognized as the standard treatment for CTEPH in most patients. ${ }^{6,7}$ The procedure involves the removal of fibrous obstructive tissue from the pulmonary arteries during circulatory arrest under deep hypothermia. The subsequent degree of relief of pulmonary hypertension is variable, but in many cases may be total with restoration of pulmonary hemodynamics to normal or near normal. The decision to operate is made on the basis of the severity of clinical symptoms, the amount and surgical accessibility of the thromboembolic lesions, the degree of impairment of pulmonary hemodynamics, and the presence of comorbidities. However, persistent pulmonary hypertension due to incomplete endarterectomy or significant secondary vasculopathy is a potential postoperative complication associated with increased morbidity and mortality. ${ }^{6}$ Inoperable patients and patients with persistent pulmonary hypertension might benefit from medical treatment with drugs that are effective in pulmonary arterial hypertension (PAH) ${ }^{8-10}$ However, exercise capacity and survival have not been improved by targeted medical therapy in randomized trials in patients with CTEPH. ${ }^{10}$

This report, based on a large-scale international prospective registry on CTEPH, documents the current surgical management of patients with CTEPH using state of the art medical care. Impact on postoperative hemodynamics and outcome, and 1-year survival is investigated.

\section{PATIENTS AND METHODS}

\section{Study Design}

This prospective registry was designed to include newly diagnosed $(\leq 6$ months) consecutive patients with CTEPH in participating centers in Europe and Canada, from February 2007 to January 2009. The registry protocol did not interfere with the management of patients by their physician. Formal ethics approvals were filed when required by country laws. This re- port focuses on those patients who underwent PEA. The observation period extended from inclusion into the registry until death/transplantation or up to 1 year after PEA. Longer-term follow-up is currently ongoing.

\section{Inclusion Criteria}

At all participating institutions, the diagnosis of CTEPH was established according to clinical guidelines valid at study initiation ${ }^{11}$ and within 6 months of inclusion in the registry. To qualify for inclusion, patients were to be 18 years or older and to have established pulmonary hypertension as confirmed by mean pulmonary artery pressure (mPAP) $25 \mathrm{~mm} \mathrm{Hg}$ or greater at rest or $30 \mathrm{~mm} \mathrm{Hg}$ or greater after exercise and pulmonary capillary wedge pressure $15 \mathrm{~mm} \mathrm{Hg}$ or less during a right heart catheterization. CTEPH was to be confirmed as the cause of pulmonary hypertension by abnormalities in ventilation/ perfusion scan (including at least 1 mismatched segmental perfusion defect), computed tomography (CT) scan, or pulmonary angiography. Abnormal CT scan/pulmonary angiography demonstrated proximal lesions (webs, bands, and narrowed vessels). Before diagnosis, patients were required to have at least 3 months of anticoagulation therapy and no PAH-specific treatment.

\section{Data Collection}

Data collected in this registry were obtained from assessments routinely performed for patients with CTEPH in clinical practice and included medical history, clinical signs and symptoms, diagnosis, and treatment procedures. The latest assessments of hemodynamics, exercise capacity, and New York Heart Association (NYHA) class, performed within 1 year after surgery, were analyzed.

\section{Surgery}

The PEA procedure was performed according to the principles previously described. ${ }^{6}$ Criteria for inoperability included distal pulmonary artery obstructions, imbalance between severity of pulmonary hypertension and morphologic lesion, PVR greater than 1500 dyn.s.cm ${ }^{-5}$, age, and comorbidity. Persistent pulmonary hypertension after PEA was defined as mPAP greater than $25 \mathrm{~mm} \mathrm{Hg}$ or echocardiographic systolic PAP greater than $40 \mathrm{~mm} \mathrm{Hg}$.

\section{Statistical Analysis}

Data analysis was performed using the SAS software package version 9.2 (SAS Institute Inc, Cary, NC).

Quantitative variables were described using median, minimum and maximum, and $95 \%$ confidence limit (CL). Wilcoxon 2-sample test was used for comparing continuous variables, and Fisher's exact test was used for categoric variables. All inferential statistical analyses were performed in an exploratory sense.

Univariate and multivariate logistic regressions were used to identify risk factors for mortality among the following parameters: confirmed pulmonary embolism, time from symptoms to PEA and from last pulmonary embolism to PEA, NYHA class, 6-minute walk distance, mPAP, PVR, initiation of PAH-specific treatment at diagnosis, circulatory arrest duration, change in PVR from diagnosis to end of intensive care, PVR at end of intensive care, and number of PEAs performed by center. Results are presented as odds ratios (OR) with corresponding 95\% CL (calculated using the Wald chi-square test).

\section{RESULTS}

\section{All-Patient Population $(n=679)$}

From February 2007 to January 2009, 679 consecutive patients recently diagnosed ( $\leq 6$ months) with CTEPH were prospectively enrolled in 1 Canadian and 26 European centers, of whom $386(56.8 \%)$ underwent surgery in 17 centers ( 2 patients underwent operation in 2 nonparticipating centers). On the basis of the surgeon's assessment, 427 
TABLE 1. Patients' characteristics at diagnosis and surgery parameters

\begin{tabular}{|c|c|}
\hline & $\begin{array}{c}\text { Operated patients } \\
(\mathbf{n}=\mathbf{3 8 6})\end{array}$ \\
\hline Gender ( $\%$ male $)$ & $54.1 \%$ \\
\hline Ethnicity (\% white) & $94.6 \%$ \\
\hline Age (y) & $60(18-84)$ \\
\hline Weight (kg) & $76(38-140)$ \\
\hline NYHA class $(\% \mathrm{III} / \% \mathrm{IV})$ & $67.9 / 12.7$ \\
\hline 6MWD (m) & $341(20-700)(\mathrm{n}=336)$ \\
\hline mPAP* $(\mathrm{mm} \mathrm{Hg})$ & $48(17-80)(\mathrm{n}=382)$ \\
\hline $\mathrm{PVR} \dagger\left(\right.$ dyn.s.cm $\left.{ }^{-5}\right)$ & $728(97-2880)(\mathrm{n}=340)$ \\
\hline Cardiac index $\left(\mathrm{L} \cdot \mathrm{min}^{-1} \cdot \mathrm{m}^{-2}\right)$ & $2.2(0.9-7.0)(\mathrm{n}=363)$ \\
\hline Time from symptoms to diagnosis (mo) & $14.6(0.5-440.7)(\mathrm{n}=372)$ \\
\hline Time from diagnosis to PEA (d) & $78(0-588)$ \\
\hline Time from symptoms to PEA $(\mathrm{y})$ & $1.5(0.1-36.7)(\mathrm{n}=372)$ \\
\hline Time from last PE to PEA (y) & $1.2(0.0-33.8)(\mathrm{n}=265)$ \\
\hline Circulatory arrest duration (min) & $35(0-146)(\mathrm{n}=378)$ \\
\hline Median mechanical ventilation time (d) & $1.2(0-45)(\mathrm{n}=381)$ \\
\hline Vena cava filter or clip ( $\%$ patients $)$ & $40.2 \%(\mathrm{n}=356)$ \\
\hline PVR at end of intensive care (dyn.s. $\mathrm{cm}^{-5}$ ) & $248(32-1440)(\mathrm{n}=280)$ \\
\hline
\end{tabular}

$6 M W D$, 6-minute walk distance; $M P A P$, mean pulmonary artery pressure; $N Y H A$, New York Heart Association; $P E$, pulmonary embolism; $P E A$, pulmonary endarterectomy; $P V R$, pulmonary vascular resistance. Values are expressed as medians with ranges or percentages; $\mathrm{n}$ : patients with assessment. *mPAP: 9 values $<25 \mathrm{~mm} \mathrm{Hg}$; 3 values $>75 \mathrm{~mm} \mathrm{Hg}$. †PVR: 13 values $<200$ dyn.s. $\mathrm{cm}^{-5}$

patients $(62.9 \%)$ were considered operable. Eventually, 386 patients $(56.8 \%)$ underwent surgery, including 13 patients documented as nonoperable; 38 operable patients refused the procedure, and 7 patients died before surgery.

\section{Operated Patient Population $(\mathbf{n}=\mathbf{3 8 6})$}

The operated patients had a median age of 60 years, and $54.1 \%$ were male (Table 1). The median time from first symptoms to diagnosis was 14.6 months. Patients presented with dyspnea $(99.2 \%)$, edema $(40.7 \%)$, fatigue $(29.5 \%)$, chest pain $(16.6 \%)$, and syncope $(16.1 \%)$.

Medical history was supportive of the thromboembolic origin of CTEPH. Previous single or recurrent pulmonary embolism was confirmed for $79.8 \%$ of all patients. CTEPH was diagnosed at a median of 12.1 months (range: 0-399 months) after the last pulmonary embolism event. Previous deep vein thrombosis was documented in $59.6 \%$ of patients $(\mathrm{n}=155 / 260)$.

Right heart catheterization (Table 1) indicated significant pulmonary hypertension with elevated PVR (median: 728 dyn.s.cm ${ }^{-5}$, mean: 799 dyn.s. $\mathrm{cm}^{-5}$ ) and mPAP (median and mean: $48 \mathrm{~mm} \mathrm{Hg}$ ). Perfusion scans were abnormal in $99.4 \%$ of patients $(n=308 / 310)$, and ventilation scans were abnormal in $16.4 \%$ of patients $(\mathrm{n}=47 / 287)$. Among patients with an abnormal perfusion scan, $5 \% / 4 \%$ had a total right/left lung perfusion defect, and among patients with reported mismatches, $94 \% / 90 \%$ had more than 1 segmental mismatch in the right/left lung and $92 \% / 93 \%$ had more than 2 subsegmental mismatches in the right/left lung. Pulmonary angiography demonstrated proximal lesions of the pulmonary artery up to the segmental level in $69.5 \%$ of patients $(n=226 / 325)$. Among patients with reported data, lesions were located in the right/left main pulmonary artery $(16 \% / 13 \%)$, lobar arteries $(72 \% / 56 \%)$, or segmental arteries $(51 / 57 \%)$. This was supported by CT, which similarly indicated proximal lesions of the pulmonary artery up to the segmental level in $69.1 \%$ of patients $(n=217 / 314)$. CT also indicated dilatation of bronchial arteries in $77.0 \%$ of patients $(n=154 / 200)$ and mosaic perfusion pattern in $82.2 \%$ of patients $(n=199 / 242)$.

At CTEPH diagnosis, $27.7 \%$ of the patients initiated at least $1 \mathrm{PAH}$-specific therapy, including phosphodiesterase type $\mathrm{V}$ inhibitor $(15.0 \%)$, endothelin receptor antagonist $(11.9 \%)$, prostacyclin analogue $(2.6 \%)$, and combined treatment $(1.8 \%)$.

\section{Surgery}

The median time from CTEPH diagnosis to surgery was 78 days. In the subgroup of patients initiating PAH-specific therapies at diagnosis, surgery was delayed (122 vs 62 days, $P<.0001$, Wilcoxon-Mann-Whitney test) and the inhospital death rate was higher ( $8.4 \%$ vs $3.2 \%$, nonsignificant, Fisher's exact test). Both observations may be related to the higher PVR reported in these patients at diagnosis compared with untreated patients (876 vs 699 dyn.s.cm ${ }^{-5}$, $P=.0005$ ) (adjustment for cofactors was not performed).

PEA was considered "complete" by the surgeon in $93.7 \%$ of patients, and the median duration of circulatory arrest was 35 minutes (Table 1). An inferior vena cava filter was placed in $40.2 \%$ of patients, and an additional cardiac procedure (patent foramen ovale/atrial septal defect closure, $\mathrm{n}=20$; coronary artery bypass graft, $\mathrm{n}=19$; tricuspid valve repair, $n=4$; aortic or mitral valve surgery, $n=2$; removal of right ventricular mass clot, $\mathrm{n}=1$; and other, $\mathrm{n}=13)$ was performed in $15.6 \%$ of patients $(\mathrm{n}=59$ / 379). Perioperative treatments were documented in 252 patients, including catecholamines $(90.5 \%)$, nitric oxide (21.4\%), phosphodiesterase type III inhibitors (13.1\%), prostanoids $(11.2 \%)$, and aprotinin $(6.7 \%)$.

\section{Surgical Complications}

Of 384 evaluable operated patients, $189(49.2 \%)$ had a perioperative complication, including infection $(18.8 \%$, of whom $65.7 \%$ had ventilator-acquired pneumonia, $6.0 \%$ had mediastinitis, $4.5 \%$ had catheter-related sepsis, and $31.3 \%$ had other), persistent pulmonary hypertension $(16.7 \%)$, neurologic $(11.2 \%)$ or bleeding $(10.2 \%)$ complications, pulmonary reperfusion edema $(9.6 \%)$, pericardial effusion $(8.3 \%)$, or need for extracorporeal membrane oxygenation (3.1\%); 18 patients died in hospital after surgery $(4.7 \%)$.

The occurrence of neurologic complications increased with increasing circulatory arrest time: $1.9 \%$ less than 20 minutes $(\mathrm{n}=52$, including 7 patients with no arrest time), $10.8 \%$ for 21 to 40 minutes $(\mathrm{n}=185), 14.6 \%$ for 41 to 60 minutes $(n=103)$, and $18.4 \%$ greater than 60 
minutes $(\mathrm{n}=38)$. The duration of circulatory arrest was a risk factor for developing neurologic complications: The OR for comparison of circulatory arrest time less than 20 minutes with more than 60 minutes was 0.09 (95\% CL, 0.01-0.74). Three patients had irreversible complications (cerebrovascular accident, $\mathrm{n}=2$; and worsening of preexisting schizophrenia, $\mathrm{n}=1$ ]) despite circulatory arrest durations comparable to the median observed for the whole population.

\section{In-Hospital and One-Year Mortality}

Within 1 year after PEA, 27 patients $(7 \%)$ had died (64 had $<1$ year of follow-up); 18 died of perioperative complications and 9 died of various causes (trauma, malignancy, multiorgan failure, pneumonia, meningitis, infection, acute respiratory distress syndrome, renal failure, and sudden death). One patient underwent lung transplantation.

Univariate analysis revealed that PVR and 6-minute walk distance at diagnosis and PVR at end of intensive care were associated with in-hospital and 1-year mortality; time from the last pulmonary embolism to PEA and initiation of PAHspecific treatment at diagnosis were also risk factors for inhospital death. Multivariate analysis further identified PVR at the end of intensive care as an independent risk factor for in-hospital death (OR, 1.79; CL, 1.11-2.88 per 100 dyn.s.cm ${ }^{-5}$ ) and for death at 1 year (OR, 1.40; CL, 1.081.83 per 100 dyn.s.cm ${ }^{-5}$ ). The 6-minute walk distance at diagnosis was also an independent factor for death at 1 year (OR, 0.40; CL, 0.21-0.79 per $100 \mathrm{~m}$ ). Survivors had a higher 6-minute walk distance and a lower PVR at diagnosis than nonsurvivors (Table 2). Mortality rates, in-hospital and at 1 year, increased with increasing values of PVR at diagnosis (Table 3) to reach $10.6 \%$ and $12.8 \%$, respectively, for those patients with a PVR exceeding 1200 dyn.s.cm ${ }^{-5}$. However, neither the mPAP at diagnosis nor the magnitude of the decrease in PVR achieved after PEA was identified as a risk factor.

The mortality rate tended to be higher in patients with no history of pulmonary embolism; it increased with increasing NYHA functional class at diagnosis and with circulatory arrest duration (Table 3), but these parameters were not risk factors, nor was the time elapsed from onset of symptoms to PEA (Table 2). The presence of an inferior vena cava filter had no obvious effect on the mortality at 1 year (Table 3 ).

No death was recorded among patients with splenectomy $(n=7)$ or ventriculoatrial shunt $(n=3)$. However, the presence of coronary disease or myocardial infarction and thrombophilic disorder was related to increased inhospital and 1-year death (Table 3).

TABLE 2. Comparison of parameters for survivors and nonsurvivors in-hospital and at 1 year

\begin{tabular}{|c|c|c|c|c|}
\hline & $\begin{array}{c}\text { In-hospital nonsurvivors } \\
(\mathbf{n}=\mathbf{1 8})\end{array}$ & $\begin{array}{c}\text { In-hospital survivors } \\
(\mathrm{n}=\mathbf{3 6 8})\end{array}$ & $\begin{array}{c}1-\mathbf{y} \\
\text { nonsurvivors } \\
(\mathbf{n}=\mathbf{2 7}) \\
\end{array}$ & $\begin{array}{c}\text { 1-y survivors } \\
(\mathbf{n}=\mathbf{3 5 9})\end{array}$ \\
\hline \multicolumn{5}{|l|}{ Time until PEA (y) } \\
\hline From symptoms & $\begin{array}{c}1.1 \\
(0.7-15.6) \\
n=15\end{array}$ & $\begin{array}{c}1.6 \\
(0.1-36.7) \\
\mathrm{n}=357\end{array}$ & $\begin{array}{c}1.2 \\
(0.7-15.6) \\
\mathrm{n}=24\end{array}$ & $\begin{array}{c}1.5 \\
(0.1-36.7) \\
\mathrm{n}=348\end{array}$ \\
\hline From last pulmonary embolism & $\begin{array}{c}5.0 \\
(0.2-29.2) \\
\mathrm{n}=8\end{array}$ & $\begin{array}{c}1.2 \\
(0.0-33.8) \\
\mathrm{n}=257\end{array}$ & $\begin{array}{c}3.0 \\
(0.2-29.2) \\
\mathrm{n}=14\end{array}$ & $\begin{array}{c}1.2 \\
(0.0-33.8) \\
\mathrm{n}=251\end{array}$ \\
\hline \multicolumn{5}{|l|}{ Diagnosis characteristics } \\
\hline 6MWD (m) & $\begin{array}{c}290 \\
(110-500) \\
n=15\end{array}$ & $\begin{array}{l}350 \\
(20-700) \\
n=321\end{array}$ & $\begin{array}{c}280 \\
(50-500) \\
n=23\end{array}$ & $\begin{array}{l}351 \\
(20-700) \\
\mathrm{n}=313\end{array}$ \\
\hline mPAP $(\mathrm{mm} \mathrm{Hg})^{*}$ & $\begin{array}{l}52 \\
(46-75) \\
\mathrm{n}=18\end{array}$ & $\begin{array}{c}48 \\
(17-80) \\
\mathrm{n}=364\end{array}$ & $\begin{array}{c}51 \\
(31-75) \\
n=27\end{array}$ & $\begin{array}{c}48 \\
(17-80) \\
\mathrm{n}=355\end{array}$ \\
\hline PVR $\left(\right.$ dyn.s.cm $\left.{ }^{-5}\right) \dagger$ & $\begin{array}{c}1091 \\
(416-2682) \\
n=15\end{array}$ & $\begin{array}{l}712 \\
(97-2880) \\
\mathrm{n}=325\end{array}$ & $\begin{array}{c}905 \\
(320-2682) \\
\mathrm{n}=24\end{array}$ & $\begin{array}{c}715 \\
(97-2880) \\
n=316\end{array}$ \\
\hline \multicolumn{5}{|l|}{ Peri/postoperative characteristics } \\
\hline Duration of circulatory arrest (min) & $\begin{array}{l}42 \\
(10-87) \\
\mathrm{n}=18\end{array}$ & $\begin{array}{l}35 \\
(0-146) \\
\mathrm{n}=360\end{array}$ & $\begin{array}{l}41 \\
(10-87) \\
n=25\end{array}$ & $\begin{array}{l}35 \\
(0-146) \\
n=353\end{array}$ \\
\hline PVR at the end of intensive care (dyn.s. $\mathrm{cm}^{-5}$ ) & $\begin{array}{c}400 \\
(191-1432) \\
\mathrm{n}=11\end{array}$ & $\begin{array}{c}245 \\
(32-1440) \\
\mathrm{n}=269\end{array}$ & $\begin{array}{c}260 \\
(164-1432) \\
\mathrm{n}=19\end{array}$ & $\begin{array}{c}245 \\
(32-1440) \\
\mathrm{n}=261\end{array}$ \\
\hline
\end{tabular}

$6 M W D$, 6-minute walk distance; $M P A P$, mean pulmonary artery pressure; $P E A$, pulmonary endarterectomy; $P V R$, pulmonary vascular resistance. Values are expressed as median with range, n. See text for ORs. *mPAP: 9 values $<25 \mathrm{~mm} \mathrm{Hg} ; 3$ values $>75 \mathrm{~mm} \mathrm{Hg}$. $\dagger$ PVR: 13 values $<200$ dyn.s. $\mathrm{cm}^{-5}$ 
TABLE 3. Impact of specific parameters on in-hospital death and death at 1 year

\begin{tabular}{|c|c|c|c|}
\hline & & $\begin{array}{c}\text { In-hospital deaths } \\
\text { n }(\%)\end{array}$ & $\begin{array}{c}\text { Deaths at } 1 \text { year } \\
\text { n }(\%)\end{array}$ \\
\hline \multicolumn{4}{|c|}{ PVR (dyn.s.cm $\left.{ }^{-5}\right), \mathrm{n}=340$} \\
\hline$<400$ & $\mathrm{n}=48$ & $0(0 \%)^{*}$ & $1(2.1 \%) \mathrm{NS}$ \\
\hline $400-800$ & $\mathrm{n}=141$ & $4(2.8 \%)^{*}$ & $8(5.7 \%) \mathrm{NS}$ \\
\hline $800-1200$ & $\mathrm{n}=104$ & $6(5.8 \%) \mathrm{NS}$ & $9(8.7 \%) \mathrm{NS}$ \\
\hline$>1200$ & $\mathrm{n}=47$ & $5(10.6 \%) \dagger$ & $6(12.8 \%) \dagger$ \\
\hline \multicolumn{4}{|c|}{ NYHA functional class, $\mathrm{n}=386$} \\
\hline I and II & $\mathrm{n}=75$ & $0 \ddagger$ & $2(2.7 \%) \mathrm{NS}$ \\
\hline III & $\mathrm{n}=262$ & $12(4.6 \%)^{*}$ & $19(7.3 \%) \mathrm{NS}$ \\
\hline IV & $\mathrm{n}=49$ & $6(12.2 \%) \dagger$ & $6(12.2 \%) \dagger$ \\
\hline \multicolumn{4}{|c|}{ History of confirmed pulmonary embolism, $n=386$} \\
\hline Yes & $\mathrm{n}=308$ & $12(3.9 \%) \mathrm{NS}$ & $19(6.2 \%) \mathrm{NS}$ \\
\hline No & $\mathrm{n}=78$ & $6(7.7 \%) \dagger$ & $8(10.3 \%) \dagger$ \\
\hline \multicolumn{4}{|c|}{ Presence of an inferior vena cava filter, $\mathrm{n}=298$} \\
\hline Yes & $\mathrm{n}=42$ & - & $2(4.8 \%) \mathrm{NS}$ \\
\hline No & $\mathrm{n}=256$ & - & $14(5.5 \%) \dagger$ \\
\hline \multicolumn{4}{|c|}{ Circulatory arrest duration, $\mathrm{n}=378$} \\
\hline$\leq 20 \min$ & $\mathrm{n}=52$ & $2(3.8 \%) \mathrm{NS}$ & $4(7.7 \%) \mathrm{NS}$ \\
\hline $21-40 \mathrm{~min}$ & $\mathrm{n}=185$ & $5(2.7 \%) \mathrm{NS}$ & $9(4.9 \%) \mathrm{NS}$ \\
\hline $1-60 \mathrm{~min}$ & $\mathrm{n}=103$ & $8(7.8 \%) \mathrm{NS}$ & $11(10.7 \%) \mathrm{NS}$ \\
\hline$>60 \min$ & $\mathrm{n}=38$ & $3(7.9 \%) \dagger$ & $3(7.9 \%) \dagger$ \\
\hline \multicolumn{4}{|c|}{ Presence of coronary disease or myocardial infarction, $n=276$} \\
\hline Yes & $\mathrm{n}=40$ & $4(10.0 \%)^{*}$ & $6(15 \%)^{*}$ \\
\hline No & $\mathrm{n}=236$ & $5(2.1 \%) \dagger$ & $12(5.1 \%) \dagger$ \\
\hline \multicolumn{4}{|c|}{ Presence of thrombophilic disorder, $\mathrm{n}=254$} \\
\hline Yes & $\mathrm{n}=141$ & $7(5.0 \%) \mathrm{NS}$ & $13(9.2 \%) \mathrm{NS}$ \\
\hline No & $\mathrm{n}=113$ & $2(1.8 \%) \dagger$ & $4(3.5 \%) \dagger$ \\
\hline
\end{tabular}

\section{Postoperative Outcome}

After surgery, hemodynamics and symptoms were markedly improved for patients with an assessment within 1 year after PEA: The median PVR decreased from 736 dyn.s.cm ${ }^{-5}$ before surgery to 248 dyn.s. $\mathrm{cm}^{-5}$ at the end of intensive care (95\% CL, 702-827 and 230-263, respectively, $\mathrm{n}=252$ ) and from 698 dyn.s.cm ${ }^{-5}$ to 235 dyn.s.cm ${ }^{-5}$ within 1 year after surgery (95\% CL, 640-874 and 211-255, respectively, $\mathrm{n}=70$ ). The median 6-minute walk distance increased from 362 to $459 \mathrm{~m}$ (95\% CL, 340-399 and 440-473, respectively, $\mathrm{n}=168$ ). NYHA functional class also improved with patients progressing from class III and IV to class I and II (Figure 1). At the end of intensive care, 64 patients $(16.7 \%)$ had persistent postoperative pulmonary hypertension. These patients had a particularly compromised preoperative hemodynamic status, which was considerably improved by surgery: The median PVR decreased from 937 dyn.s.cm ${ }^{-5}$ before surgery to 396 dyn.s. $\mathrm{cm}^{-5}$ at the end of intensive care (95\% CL, 822-1120 and 320-450, respectively, $\mathrm{n}=49$ ). The median 6-minute walk distance tended to increase from 288 to $385 \mathrm{~m}$ within 1 year after surgery (95\% CL, 250-362 and 324-480, respectively, $\mathrm{n}=25)$.

\section{Center Expertise}

Of 386 operated patients, 141 (36.5\%) underwent operation in centers performing more than 50 PEAs per year (based on data from 2004-2006) (Table 4). In these centers, the mortality rates tended to be lower, but the magnitude of the decrease in PVR achieved after surgery was less when compared with that of centers performing fewer PEAs per year. However, the center expertise as defined by the

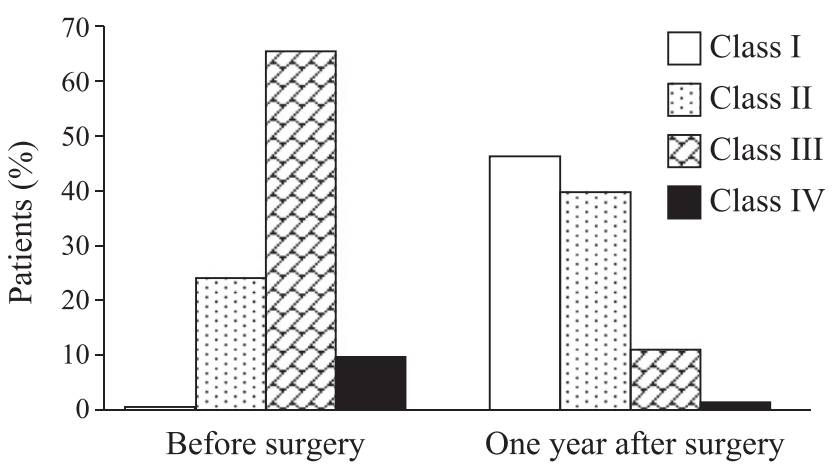

FIGURE 1. NYHA functional class before surgery and within 1 year after surgery $(\mathrm{n}=221)$. 


\begin{tabular}{|c|c|c|c|c|}
\hline & \multicolumn{4}{|c|}{ Average no. of PEAs per year } \\
\hline & 1-10 & 11-50 & $>\mathbf{5 0}$ & Combined \\
\hline No. of centers performing PEA, $\mathrm{n}(\%)$ & $6(35.3 \%)$ & $8(47.1 \%)$ & $3(17.6 \%)$ & $17 *$ \\
\hline No. of patients, $n(\%)$ & $54(14.0 \%)$ & $191(49.5 \%)$ & $141(36.5 \%)$ & $386^{*}$ \\
\hline $\begin{array}{l}\text { Change in PVR from diagnosis to end of intensive } \\
\text { care, dyn.s. } \mathrm{cm}^{-5} \text {, median (range), } \mathrm{n}\end{array}$ & $\begin{array}{c}-476 \mathrm{NS} \\
(-1760 \text { to } 80) \\
n=43\end{array}$ & $\begin{array}{c}-476 \dagger \\
(-2256 \text { to } 22) \\
\mathrm{n}=144\end{array}$ & $\begin{array}{c}-400 \ddagger \\
(-2261 \text { to } 554) \\
n=65\end{array}$ & $\begin{array}{c}-457 \\
(-2261 \text { to } 554) \\
n=252\end{array}$ \\
\hline \multicolumn{5}{|l|}{ Death, $\mathrm{n}(\%) \S$} \\
\hline In-hospital & $4(7.4 \%) \mathrm{NS}$ & $9(4.7 \%) \mathrm{NS}$ & $5(3.5 \%) \S$ & $18(4.7 \%)$ \\
\hline $1 \mathrm{y}$ after PEA & $6(11.1 \%) \mathrm{NS}$ & $14(7.3 \%) \mathrm{NS}$ & $7(5.0 \%) \S$ & $27(7.0 \%)$ \\
\hline
\end{tabular}

number of PEAs performed per year was not a risk factor for mortality.

\section{DISCUSSION}

This study, based on a large-scale international prospective non-interventional registry on incident CTEPH cases, documents the current surgical management and outcome of patients undergoing PEA in Europe and Canada. Previously, large patient series have been derived retrospectively from medical and surgical databases from San Diego and Paris, ${ }^{6,7}$ with 2 recent reports including a PAH-controlled cohort study in Europe ${ }^{4}$ and a national registry in the United Kingdom. ${ }^{12}$ The present investigation supports the role of exercise capacity in predicting 1-year mortality and of postoperative PVR as a predictor of in-hospital and 1-year mortality in patients with CTEPH.

The demographics of the operated patients with CTEPH included in the registry are in line with previous reports. $^{6,7,13,14}$ CTEPH was almost equally frequent in men and women in their sixth decade of life. The greater than usual occurrence of pulmonary embolism and deep vein thrombosis ${ }^{7}$ has also been observed in recent studies ${ }^{4}$ and may have resulted from increased awareness of thrombosis in the participating centers.

The University of California San Diego has performed the most PEA procedures in the world and has set the surgical standards. The standard technique, ${ }^{6}$ followed by most centers, involves cooling to $20^{\circ} \mathrm{C}$ with periods of circulatory arrest to allow a clear operative field for distal endarterectomy. The fundamental compromise is between allowing enough arrest time for a complete endarterectomy and limiting the time of circulatory arrest. With relatively short arrest periods (20 minutes per side), permanent cerebral damage is rare after PEA surgery. However, the duration of circulatory arrest is associated with the incidence of temporary neurologic dysfunction in patients undergoing aortic surgery. ${ }^{15,16}$ Reich and colleagues ${ }^{15}$ reported that a circulatory arrest of 25 minutes or more was associated with memory and fine motor deficits. Our study has demonstrated that an increased duration of circulatory arrest during PEA surgery is a risk factor for devel- oping neurologic complications. However, most neurologic complications were temporary, and, as previously reported, ${ }^{17}$ the use or duration of circulatory arrest did not affect mortality, but failure to reduce PVR did. ${ }^{6,14}$ Although the median duration of total circulatory arrest was only 35 minutes, some patients did not have any arrest time and others had a cumulative time maximum of 146 minutes. These extremes arose because 1 center used a technique to try and avoid arrest and another used multiple very short periods. Modifications of the PEA procedure intended to avoid circulatory arrest have been described ${ }^{18}$ but have not been demonstrated to provide substantial benefit when compared with the traditional technique.

The current PEA procedure provides remarkable results, with an in-hospital mortality rate in recent worldwide series ranging from $4.4 \%$ to $16 \% .^{6,13,14,19,20}$ The low mortality rate $(4.7 \%)$ reported is in line with continuously improving surgical results due to a combination of increased experience and adequate selection of surgically eligible patients. The inclusion of exclusively newly diagnosed patients into the registry may also have contributed to the low mortality rate observed. Mortality tended to be lower in high-volume centers despite a lower decrease in PVR; it is possible that small centers performed operations in patients with proximal disease and successfully decreased PVR while referring the more distal cases to larger centers.

Postoperative PVR was found to be an independent risk factor for in-hospital and 1-year mortality, whereas preoperative PVR was only identified in univariate analysis. Most studies have associated high preoperative PVR (ie, >900 1100 dyn.s.cm ${ }^{-5}$ ) with increased PEA mortality. ${ }^{6,7,12,17}$ As reported in 1 series, ${ }^{7}$ we observed an almost linear relationship between preoperative PVR and in-hospital mortality. Mortality is also strongly related to the postoperative PVR, and a decrease to less than 500 dyn.s.cm ${ }^{-5}$ has been reported as optimal. ${ }^{6,14}$ The present registry confirms that the best operative outcome requires significant early reduction of PVR.

The 6-minute walk test is a well-established prognostic tool in idiopathic $\mathrm{PAH},{ }^{21}$ but it has not been validated in 
CTEPH. Few studies have linked the mortality of patients with CTEPH with exercise capacity. ${ }^{12,22}$ In the present registry, nonsurvivors had a worse preoperative 6-minute walk distance than survivors and exercise capacity was predictive of 1-year mortality.

The time from last pulmonary embolism to PEA was a risk factor for in-hospital mortality in univariate analysis. Because the triggering event in the development of CTEPH is an unresolved pulmonary embolism in many patients, earlier referral to surgery after such an event might avoid the occurrence of a secondary vasculopathy in the unaffected areas of the pulmonary vascular tree.

Excessive perioperative mortality in patients with CTEPH with specific medical conditions, such as splenectomy, ventriculoatrial shunt, and infected pacemaker, ${ }^{19}$ has not been systematically reported. ${ }^{12}$ In the present registry, no death cases were reported for patients with these conditions, although the presence of coronary disease, myocardial infarction, or thrombophilic disorder was associated with increased mortality.

Among survivors, most of the improvement in hemodynamics was achieved immediately after PEA, as an immediate result of the relief of central mechanical obstruction. The most impressive aspect of the postoperative outcome was the improvement of clinical symptoms; the majority of patients improved their walk distance and returned to NYHA class I or II during the first year after surgery. This immediate and sustained benefit from surgery has been reported in individual series by numerous groups throughout the world, ${ }^{13,14,20,23}$ demonstrating that postoperative normalization of hemodynamic and functional status could be achieved. However, despite careful patient selection based on the anticipated hemodynamic improvement, the postoperative PVR failed to return to normal or near normal levels by the end of intensive care in $16.7 \%$ of patients. Improvement may not have been sufficient in these patients with more compromised hemodynamics and exercise capacity at diagnosis. They may have more vasculopathy ${ }^{6}$ preventing them from receiving the full benefit from surgery.

Over the last decade, several novel therapies have been developed for $\mathrm{PAH}$, including prostacyclin analogs, endothelin receptor antagonists, and phosphodiesterase type $\mathrm{V}$ inhibitors. ${ }^{8-10}$ Evidence of efficacy in PAH, coupled with studies showing histopathologic similarities between $\mathrm{CTEPH}$ and $\mathrm{PAH}$, has provided a rationale to extend the use of these medications to the treatment of CTEPH. ${ }^{7}$ As a consequence, the prescription of these medications, even in operable CTEPH, has increased over the past several years. In the UK registry, ${ }^{12} 29 \%$ of the surgical patients received PAH-specific therapy before surgery during the period 2001-2002, compared with $65 \%$ for the period 2003-2006. Jensen and colleagues ${ }^{24}$ reported an increase from $19.9 \%$ in 2005 to $37 \%$ in 2007 . We similarly observed that $27.7 \%$ of the surgical patients initiated at least $1 \mathrm{PAH}$-specific therapy at diagnosis. Selected "high-risk" patients might benefit from PAH-specific therapies to optimize pulmonary hemodynamics before surgery. Moreover, in patients whose surgery is delayed owing to limited medical resources, pretreatment may prevent clinical deterioration. Several open-label studies suggest a beneficial effect for patients with severe CTEPH waiting for surgery who are treated with prostacyclin ${ }^{8}$ or bosentan. ${ }^{25}$ However, although the benefits of preoperative medical treatment have to be confirmed, the risks may include unnecessary delays to a potentially curative surgical intervention.

\section{CONCLUSIONS}

This contemporary registry highlights current practice and surgical management of patients with CTEPH. The PEA surgery was associated with a low in-hospital mortality rate and improvements in hemodynamics and exercise capacity. The duration between last pulmonary embolism and PEA was identified as a risk factor for in-hospital mortality, thus emphasizing the importance of early referral to surgery. Preoperative exercise capacity was independently predictive of 1-year mortality, whereas postoperative PVR was an independent factor of in-hospital and 1-year mortality. Whether the contemporary management of patients with CTEPH yields a better prognosis than observed in the past will be evaluated in the ongoing 3-year follow-up of this large patient cohort.

The authors acknowledge the contribution of the following investigators: Austria: H. Olschewski, Medical University Graz, Graz; Canada: M. de Perrot Toronto General Hospital, Toronto; Czech Republic: P. Jansa, Charles University, Prag; Denmark: B. O. Kristensen, Aarhus University, Aarhus; Germany: M. Hoeper, Medizinische Hochschule Hannover, Hannover; H. Bremer, Universitätsklinikum Freiburg, Freiburg; J. Behr, Klinikum der Universität München-Grosshadern, München; R. Ewert, Ernst Moritz Arndt Universität, Greifswald; Hungary: K. Karlocai, National Cardiology Institute, Budapest; Ireland: S. P. Gaine, Mater Misericordiae University Hospital, Dublin; Italy: M. Confalonieri, University Hospital of Cattinara - Trieste, Trieste; D. Vizza, Policlinico Universitario Umberto I, Roma; Netherlands: A. Boonstra, Vrije Universiteit Medisch Centrum, Amsterdam; R. J. Snijder, St Antonius Ziekenhuis, Nieuwegein; P. Bresser, Academic Medical Center, Amsterdam; Poland: J. Lewczuk, Regional Hospital and Medical University, Wroclaw; A. Torbicki, Institute Tuberculosis and Lung Diseases, Warszawa; Romania: M. A. Bogdan, National Institut de Pneumologie 'M.Nasta,' Bukarest; Slovakia: I. Šimková, Slovak Medical University and National Institute of Cardiovascular Diseases, Bratislava; Spain: J. Barberà, Hospital Clínic-CIBER Enfermedades Respiratorias, University of Barcelona; M. A. Gomez-Sanchez, Hospital Universitario 12 Octubre, Madrid; Switzerland: R. Speich, Universitätspital Zürich, Zürich.

The authors also thank Sylvie I. Ertel (Sundgau Medical Writer, France) for editorial assistance, and Jürgen Müller and Werner Baurecht (Acromion GmbH, Germany) for statistical analyses. 


\section{References}

1. Moser KM, Auger WR, Fedullo PF. Chronic major-vessel thromboembolic pulmonary hypertension. Circulation. 1990;81:1735-43.

2. Hoeper MM, Mayer E, Simonneau G, Rubin LJ. Chronic thromboembolic pulmonary hypertension. Circulation. 2006;113:2011-20.

3. Pengo V, Lensing AW, Prins MH, Marchiori A, Davidson BL, Tiozzo F, et al. Incidence of chronic thromboembolic pulmonary hypertension after pulmonary embolism. N Engl J Med. 2004;350:2257-64.

4. Bonderman D, Wilkens H, Wakounig S, Schafers HJ, Jansa P, Lindner J, et al. Risk factors for chronic thromboembolic pulmonary hypertension. Eur Respir J. 2009;33:325-31.

5. Riedel M, Stanek V, Widimsky J, Prerovsky I. Longterm follow-up of patients with pulmonary thromboembolism. Late prognosis and evolution of hemodynamic and respiratory data. Chest. 1982;81:151-8.

6. Jamieson SW, Kapelanski DP, Sakakibara N, Manecke GR, Thistlethwaite PA, Kerr KM, et al. Pulmonary endarterectomy: experience and lessons learned in 1,500 cases. Ann Thorac Surg. 2003;76:1457-64.

7. Dartevelle P, Fadel E, Mussot S, Chapelier A, Herve P, de Perrot M, et al. Chronic thromboembolic pulmonary hypertension. Eur Respir J. 2004;23:637-48.

8. Bresser P, Fedullo PF, Auger WR, Channick RN, Robbins IM, Kerr KM, et al. Continuous intravenous epoprostenol for chronic thromboembolic pulmonary hypertension. Eur Respir J. 2004;23:595-600.

9. Reichenberger F, Voswinckel R, Enke B, Rutsch M, El Fechtali E, Schmehl T, et al. Long-term treatment with sildenafil in chronic thromboembolic pulmonary hypertension. Eur Respir J. 2007;30:922-7.

10. Jais X, D'Armini AM, Jansa P, Torbicki A, Delcroix M, Ghofrani HA, et al. Bosentan for treatment of inoperable chronic thromboembolic pulmonary hypertension: BENEFiT (Bosentan Effects in iNopErable Forms of chronIc Thromboembolic pulmonary hypertension), a randomized, placebo-controlled trial. J Am Coll Cardiol. 2008;52:2127-34.

11. Galie N, Torbicki A, Barst R, Dartevelle P, Haworth S, Higenbottam T, et al. Guidelines on diagnosis and treatment of pulmonary arterial hypertension. The Task Force on Diagnosis and Treatment of Pulmonary Arterial Hypertension of the European Society of Cardiology. Eur Heart J. 2004;25:2243-78.

12. Condliffe R, Kiely DG, Gibbs JS, Corris PA, Peacock AJ, Jenkins DP, et al. Prognostic and aetiological factors in chronic thromboembolic pulmonary hypertension. Eur Respir J. 2009;33:332-8.

13. Condliffe R, Kiely DG, Gibbs JS, Corris PA, Peacock AJ, Jenkins DP, et al. Improved outcomes in medically and surgically treated chronic thromboembolic pulmonary hypertension. Am J Respir Crit Care Med. 2008;177: 1122-7.

14. Thistlethwaite PA, Kaneko K, Madani MM, Jamieson SW. Technique and outcomes of pulmonary endarterectomy surgery. Ann Thorac Cardiovasc Surg. 2008; $14: 274-82$.

15. Reich DL, Uysal S, Sliwinski M, Ergin MA, Kahn RA, Konstadt SN, et al. Neuropsychologic outcome after deep hypothermic circulatory arrest in adults. $J$ Thorac Cardiovasc Surg. 1999;117:156-63.

16. Hagl C, Ergin MA, Galla JD, Lansman SL, McCullough JN, Spielvogel D, et al. Neurologic outcome after ascending aorta-aortic arch operations: effect of brain protection technique in high-risk patients. J Thorac Cardiovasc Surg. 2001;121: 1107-21.

17. Hartz RS, Byrne JG, Levitsky S, Park J, Rich S. Predictors of mortality in pulmonary thromboendarterectomy. Ann Thorac Surg. 1996;62:1255-60.

18. Thomson B, Tsui SS, Dunning J, Goodwin A, Vuylsteke A, Latimer R, et al. Pulmonary endarterectomy is possible and effective without the use of complete circulatory arrest-the UK experience in over 150 patients. Eur J Cardiothorac Surg. 2008;33:157-63

19. Bonderman D, Skoro-Sajer N, Jakowitsch J, Adlbrecht C, Dunkler D, Taghavi S, et al. Predictors of outcome in chronic thromboembolic pulmonary hypertension. Circulation. 2007;115:2153-8.

20. Matsuda H, Ogino H, Minatoya K, Sasaki H, Nakanishi N, Kyotani S, et al. Long-term recovery of exercise ability after pulmonary endarterectomy for chronic thromboembolic pulmonary hypertension. Ann Thorac Surg. 2006;82: 1338-43.

21. Miyamoto S, Nagaya N, Satoh T, Kyotani S, Sakamaki F, Fujita M, et al. Clinical correlates and prognostic significance of six-minute walk test in patients with primary pulmonary hypertension. Comparison with cardiopulmonary exercise testing. Am J Respir Crit Care Med. 2000;161(2 Pt 1):487-92.

22. Suntharalingam J, Goldsmith K, Toshner M, Doughty N, Sheares KK, Hughes R, et al. Role of NT-proBNP and 6MWD in chronic thromboembolic pulmonary hypertension. Respir Med. 2007;101:2254-62.
23. Mayer E, Dahm M, Hake U, Schmid FX, Pitton M, Kupferwasser I, et al. Midterm results of pulmonary thromboendarterectomy for chronic thromboembolic pulmonary hypertension. Ann Thorac Surg. 1996;61:1788-92.

24. Jensen KW, Kerr KM, Fedullo PF, Kim NH, Test VJ, Ben-Yehuda O, et al Pulmonary hypertensive medical therapy in chronic thromboembolic pulmonary hypertension before pulmonary thromboendarterectomy. Circulation. 2009;120: 1248-54.

25. Reesink HJ, Surie S, Kloek JJ, Tan HL, Tepaske R, Fedullo PF, et al. Bosentan as a bridge to pulmonary endarterectomy for chronic thromboembolic pulmonary hypertension. J Thorac Cardiovasc Surg. 2009;139:85-91.

\section{Discussion}

Dr Thoralf Sundt (Rochester, Minn). I have a few questions for you. First, I congratulate you on doing such a multicenter study, and those who have attempted to do even a registry like this can appreciate the complexity of it. This is a complex condition, and if we are going to make progress, we do need to do these kinds of studies, but it is a lot of work just to collect the information. I tip my hat to you on that, and really with a remarkably low mortality rate.

I have a fairly technical question. In our institution, it is almost impossible anymore to get the interventional radiologists to do an adequate pulmonary angiogram, and they have themselves begged us to use high-resolution CT scanning, and we have basically abandoned pulmonary arteriography in favor of CT scanning with reconstructions. I wonder if the same is true in Europe.

Dr Mayer. I have to disagree. I believe that for an adequate evaluation of operability, pulmonary angiography is still the standard technique, and I do believe that CT angiography, even highresolution CT, 256-row CT, is not an adequate procedure, because most of the radiologists believe they have to show clot in the pulmonary arteries, but we are not speaking about clot, we are speaking about 1-mm obstructions in segmental arteries. So it might be possible to use it in central disease, but it is not possible to use it in peripheral distal disease.

Dr Sundt. The second question relates to the learning curve. You have a large number of patients but also a large number of centers, and you showed us the relationship between mortality rate and center experience, but what about surgeon experience? Certainly for me this has been a difficult operation with a steep learning curve, and I still believe I am on that learning curve. I wonder if you have any information about the relationship on a surgeonby-surgeon basis related to the learning curve, not just for mortality rate but residual PVR and, for that matter, the judgment about operability.

Dr Mayer. We do not have the data for the whole registry. We have the data for single centers. But notably, in the registry, you had a look at the article, we could demonstrate that the centers with low volume had a better postoperative PVR reduction compared with the centers with high volume, probably because of the intense selection of proximal candidates. So in centers with high volume, many distal endarterectomies are performed with some grade of microvascular disease, and therefore the decrease of PVR might not be as hard compared with proximal disease.

We know that the learning curve is intense, not only for the surgeon but also for the people who make the evaluation and for postoperative care, but we don't have the data for the whole registry. 
Dr Sundt. My last question really is a political one. We heard yesterday about regionalization of lobectomy in Canada and in this same vein in terms of the learning curve. Do you think a relatively uncommon procedure like this should be done in only a few centers, in a center of excellence type model, or what is your view on that?

Dr Mayer. I think this operation should be performed only in excellent centers, and the situation in Europe is very different. For example, in England and France, there is only 1 center. Every patient with CTEPH who undergoes an operation is referred to Paris or Cambridge. In other countries there are centers with high volume, but there are also several centers doing 2 or 3 cases per year. This is not a good idea, because 1 death of 3 cases is $33 \%$.

Dr Michael Madani (San Diego, Calif). As you know, we have been performing pulmonary endarterectomies for more than 2 decades now, and we have done more than 2500 of these cases. It is clear that this condition is still severely underdiagnosed and a large number of patients are being denied surgery, even after the diagnosis is made. What is really disturbing, in the United States, and perhaps more in Europe, is a wider application of the newer vasodilator and antiproliferative agents preventing or delaying surgical referrals. Although I agree that there may be eventually a role for these agents in patients with residual pulmonary hypertension after PEA or in preoperative patients when there is a severe mismatch between clot burden and degree of pulmonary hypertension, the bottom line is that this is a mechanical condition and requires a mechanical solution.

The issue of operability is really the key issue of my discussion. We believe that if there is evidence of thromboembolic disease, surgery should be performed. This is particularly important, as you just mentioned, with the CT scan, as well as the angiogram, because most preoperative studies tend to underestimate the true clot burden. We have found that more than $90 \%$ of patients referred to us who are deemed inoperable at other centers or because they have so-called distal disease really experience significant hemodynamic improvement after full endarterectomy. The mortality rate in the last 500 in our series is less than $3 \%$. I would like to know how this registry will address this issue of inoperability among the 17 centers, including those with such low volumes?

Dr Mayer. The problem is that it was a noninterventional registry, so we took the data from the different centers. I completely agree that the evaluation of operability is also a factor of learning curve, and it is the same in our center, that many patients are sent deemed inoperable, and they are clearly operable because sometimes they even have poor diagnostics. I do believe that every patient with diagnosed CTEPH should be referred to a surgical center without delay and without medical treatment. There are no data supporting preoperative medical treatment.

Dr Madani. I have one more question for you. I noticed in the article that you used a PVR of 1500 as the cutoff for operability and that in your data you had patients with higher PVRs. If you could clarify why you are using a PVR of 1500 as a cutoff?

Dr Mayer. No, we are not using a PVR of 1500 . We were asking the surgeons why they did not perform PEA, and we were asking for reasons, and one reason was very high PVR. Patients with high PVRs, as seen in the numbers, were not excluded from surgery.

Dr R. Duane Davis (Durham, NC). The incidence of acute lung injury or ischemia-reperfusion or whatever you want to call it seemed to be dramatically decreasing over the time. Is this a learning effect or the application of essentially the reperfusion strategies that we use in lung transplant? Have you standardized that across the centers or are you using this platform to improve process across the centers in terms of an educational standpoint?

Dr Mayer. That is what we want to do. We want to use this platform for future studies, because there are no studies on perioperative treatment at the moment. And it is true, over the last 20 years, reperfusion lung injury has been significantly decreased and is not a clinically significant problem anymore. We don't know the exact reasons for that, but we believe that a faster operation and better postoperative care with regard to hemodynamics (eg, keeping the cardiac index low) are good measures to reduce pulmonary reperfusion edema, but it is a multifactorial development. But it has decreased significantly, you are right. 